\title{
THE EFFECTS OF THE FUEL INJECTION PRESSURE ON THE PERFORMANCE AND EMISSION CHARACTERISTICS OF VCR ENGINE FUELLED WITH PUPAE BIODIESEL-DIESEL BLENDS
}

\author{
PRADEEP N R ${ }^{1}$, Dr. S KUMARAPPA ${ }^{2}$, Dr. B M KULKARNI ${ }^{3}$ \\ ${ }^{1,2}$ Mechanical Engineering, BIET, Karnataka, India \\ ${ }^{3}$ Chemical Engineering, BIET, Karnataka, India
}

\begin{abstract}
The usage of diesel Engine day by day extended considering their low fuel use and high efficiencies. A few endeavors were made for search of elective fuels due to extended natural contamination and exhaustion of conventional nonsustainable energy sources and prevailing in the improvement of Biodiesel as an elective fuel. An endeavor was made on Direct Injection Compression Ignition (DI-CI) engine using Pupae oil methyl ester blended in with diesel in various degrees to consider the engine performance and emission (outflow) at different injection pressures. The tests were led at consistent load at various injection pressures (200, 220, 240, 260 and 280 bar). In the current work performance qualities like Brake thermal efficiency (BTE), Brake Specific fuel consumption (BSFC), exhaust gas temperature (EGT) and outflow attributes like carbon monoxide (CO), oxides of nitrogen (NOX), unburnt hydrocarbon (UHC) and smoke opacity had been researched. From the outcomes it is seen that 260 bar injection pressure causes better execution and improved emission qualities, for all the fuel blends.
\end{abstract}

KEYWORDS: Pupae oil Methyl Ester (POME), transesterification, Diesel engine performance, emission (outflow) and injection pressure (IP)

Received: Jun 08, 2020; Accepted: Jun 28, 2020; Published: Sep 17, 2020; Paper Id.: IJMPERDJUN20201311

\section{INTRODUCTION}

Biodiesel can be delivered from vegetable oils, animal fats, or their wastes by various techniques like dilution, micro emulsification, and transesterification. The most favored strategy for delivering biodiesel is transesterification [1]. The most usually utilized feedstocks in the biodiesel creation have been rapeseed, palm, sunflower, and soybean in everywhere on over the world [2]. Since the unadulterated vegetable oils are critical crude materials in food industry, their use in the biodiesel creation isn't conservative and handy [3]. The production expenses of biodiesel fuels are as yet higher than the standard diesel fuels and they are regularly tax-favored for special purposes [4]. There is a great economic challenge for the commercialization of biodiesel fuels worldwide inferable from the utilization of non-eatable oil (animal fat/larva) in the creation of biodiesel. Also, with the wealth of crude materials (horticultural waste, animal fats, squander oil, green algae), a biodiesel improvement plan is a decent answer for inspire farmers to participate in supportable farming in creating nations. So biodiesel created from these sources has been proposed as the superior inexhaustible source [5]. In the course of recent decades, different biodiesel for diesel engines have been investigated and concentrated on the performance, outflow and ignition attributes by numerous analysts. They examined that the impact of working boundaries like injection timing (IT) and injection pressure (IP) on the engine ignition trademark is very significant. IT and IP influences 
significant effects on the performance attributes of biodiesel fuelled engines [6]. Variation in fuel IT and fuel IP prompts the uniqueness in burning peculiarity that worries deviation in the outflow qualities of biodiesel fuelled diesel engine, which have been assessed in our past research paper [7].

K B Mutyalu et al., [8] examined the direct injection compression ignition (DI-CI) engine utilizing sheaolein methyl ester mixed (blended) with diesel in different extents for the engine performance and outflow at various IP. The tests were directed at consistent load at various IP (190, 200, 210, 220, 230 bar). A. Anbarasu et al., [9] examined the performance and outflow qualities of a CI engine with diesel and mixes of canola biodiesel emulsion at 200, 220 and 240 bar. M.S. Shehata et al., [9] worked at corn and soybean fuel mixes at the most suggested mixing proportion of $20 \%$ biodiesel (C20 and S20) with customary diesel fuel as elective fuel for diesel engines. A progression of tests are led on four-stroke single chamber air cooled direct injection (DI) diesel engine at various engine speed, loads and IP of 180, 190 and 200 bar. The significant end is that, the expanded injection pressure gives better outcomes with respect to the engine performance boundaries (both BSFC and BTE) in examination with instance of the original IP for every tried fuel, consequently the best Results are gotten at high IP of 200 bar. G. Jamuna Rani, Y.V. et al., [11] examined the exhibition and fumes discharge attributes of direct injection, 4-stroke, water cooled, single chamber diesel engine utilizing mahua biodiesel mix B25 (75\% Diesel + 25\% Mahua biodiesel) at different fuel IP (200, 220 and 240 bar). Ho Young Kim et al., [12] examined the burning attributes and outflow levels of pollutants were estimated by fluctuating the fuel IP (200 to 380 bar) with palm oil biodiesel. S V Channapattana et al., [13] explored the impact of fuel IP (180,210 and 240 bar) on the exhibition and emission qualities of single cylinder VCR, DICI engine fuelled with the mixes of honne biodiesel and diesel. Thalari Vasantha et al., [14] examined the cashew nutshell oil (CNSL) and diesel in a single cylinder, 4-stroke water cooled light duty diesel engine at various IP 180, 195 and 210 bar. Kandasamy Muralidharan et al., [15] explored the impact of fuel IP on the engine discharge qualities of a single cylinder DI diesel engine utilizing pongamiapinnata methyl ester and its mixes with diesel fuel from 0-30\% with an addition of 5\% at full load. The tests were directed at five distinctive IP (190, 200, 210, 220 and 230 bar) by methods for changing injector spring strain. K. Nanthagopal et al., [16] explored the impact of Calophylluminophyllum methyl ester on diesel engine execution, discharge and burning qualities at various IP (200, 220 and 240 bars). Hariprasad T [17] explored the palm oil methyl ester as pilot fuel in dual fuel engine to discover the impacts of IP on emissions and engine performance in a diesel engine. IP was changed from 190 bar to 230 bar in test. Pradip Lingfa et al.,[18] examined the exhibition and discharge attributes of diesel and Tung biodiesel (TB) mixes (TB10, TB15, TB20 and TB50) at three distinctive injector opening pressure (150 bar, 200 bar and 250 bar) individually. Fuel injection opening pressure was fluctuated by changing the spring pressure of the needle valve of injector spout. Preetham Churkunti et al., [19] investigated the impact of fuel IP on ultra-low sulphur diesel (ULSD), Waste Cooking Oil (WCO) biodiesel, and their mixes in a single-cylinder CI engine. T. Basavaraja et al., [20] researched the fuel properties of pongamia oil (honge oil), pongamia methyl ester and its mixes with diesel fuel from 10 to 50\% by volume and running in a single-cylinder 4-stroke diesel engine with these fuels at various IP (160 bar, 180 bar, 200 bar, 220 bar).

Literature study shows that numerous tests examines have been directed on the engine performance and fumes discharge attributes when using distinctive IP with various proportions of mixes among biodiesel and diesel fuels in the diesel engines. Besides, there is a growing interest for request to decide the suitable engine working conditions. Along these lines in the current work it is critical to sum up the impact of IP on the performance and emissions qualities of a pupae biodiesel and its mixes for the successful burning in modern day variable compression ratio (VCR) engine. 


\subsection{Present Work}

The point of the current work is to utilize pupae oil methyl ester (POME) as a substitute for diesel in factor pressure proportion (VCR) engine. A single chamber diesel engine test rig was custom-made to work in diesel-biodiesel fuel-mixes (blends) mode. In engine trial, diesel was utilized as primary fuel and POME was utilized as secondary fuel. To improve the performance of the VCR engine, the injector opening pressure were expanded. The injector opening pressure is 200 bar. The consistency of the POME is higher than diesel and thus to improve the performance of the VCR engine, the injector opening pressure was expanded to $220,240,260$ and 280 bar.

\subsection{Pupae oil}

Pupae oil is created from dead silkworm pupae. One of significant source is found in silk reeling industry as waste pupae. It is acceptable wellspring of fats and lipids. Silk is known everywhere on over the world for its special brilliant shading, solidness and surface. Silk involves a conspicuous situation in the social legacy of the Indian public. Silkworm rearing, reeling and weaving of silk likewise speak to the tradition of India. A pupae, which establishes the significant bit of the cocoon weight, is an inevitable by-product created in enormous amount (75-85\%) during the cocoon production. In India, around 16,525 ton of crude silk is delivered from that 3,305 ton of pupae oil per annum can be created, so it can halfway full fill the prerequisite of petroleum product [21]. Accordingly, pupae oil with most noteworthy creation and productivity is a promising feedstock for bio-diesel production particularly in india.

\subsection{Pupae oil Methyl Ester}

Pupae oil is utilized for pupae oil methyl ester (POME) preparing in this examination. POME is set up by transesterification reaction. In transesterification reaction, one mole of the weighty tri-glyceride and three moles of methyl liquor yields one mole of glycerol and three moles of lighter unsaturated fat methyl esters mixes. Without the utilization of an catalyst the reaction would be moderate and furthermore inadequate. A temperature of $60^{\circ} \mathrm{C}$ to $70^{\circ} \mathrm{C}$ would be required for the reaction to get successful. Likewise an energetic unsettling of the reactants would be required thus a motorized stirrer in the reaction vessel gets fundamental. Different catalyst can be utilized, the most well-known are the base catalyst, as $\mathrm{NaOH} / \mathrm{KOH}$. Toward the finish of the reaction, the blends are kept at the ambient temperature $25-30^{\circ} \mathrm{C}$ for ten hours and afterward drained the settled glycerin layer. At long last, the remaining methanol in methyl ester blends is dissipated. At that point the completed item is Pupae oil methyl ester (POME) is as appeared in figure 1. The ester conversion pace of POME is over $86 \%$.

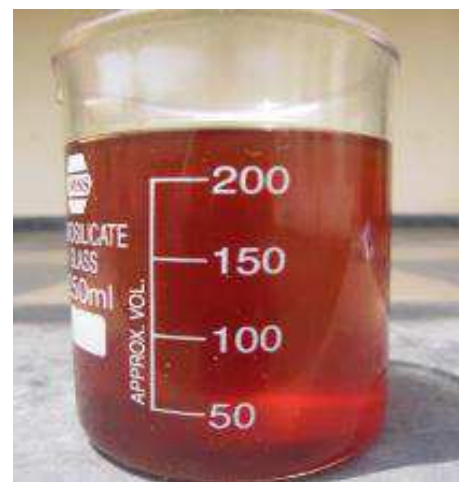

Figure 1: Pupae oil methyl ester 


\section{2}

EXPERIMENTAL SETUP

A single cylinder, 4-stroke, water cooled, DI-VCR electronic diesel engine test rig was custom fitted to work in dieselbiodiesel fuel-mixes mode. The point of interest of the engine utilized for present work is delineated in Table 1.The schematic of the test arrangement is appeared in Fig. 2. The dynamometer utilized for loading the engine is of eddy current type. The gradual turning encoder with $360 \mathrm{ppr}$ is utilized for crank position and speed estimation. The fluid fuel stream rate was estimated on the volumetric basis utilizing a burette and recorded in electronic diesel engine test rig. AVL DiGas 444G fumes (exhaust) gas analyzer was utilized for estimating fumes emanations and an AVL 437C smoke meter was utilized to quantify the smoke discharge. The VCR engine was turned over by hand cranking with pupae oil methyl ester (POME) as fuel and its mixes with diesel brought into the chamber through the mechanical injection framework. At consistent state condition, significant observations, for example, fuel stream rate, air flow rate, fumes gas temperature, chamber pressure and fumes outflows were recorded.

\subsection{Experimental Methodology}

The VCR engine is turned over by utilizing standard diesel and when the engine arrives at the working temperature, $20 \%$ load is applied continuously. The warm up period closes when cooling water temperature is balanced out at $60^{\circ} \mathrm{C}$. The tests are led at the evaluated speed of $1500 \mathrm{rpm}$ at $80 \%$ load. In each test, fuel utilization and fumes gas emissions, for example, carbon monoxide (CO), unburnt hydrocarbon (UHC), nitrogen oxides (NOx) are estimated by utilizing fumes gas analyser and smoke opacity were noted by utilizing smoke meter. From the initial estimation, BTE, BSFC and EGT as for injection pressure of 200, 220, 240, 260 and 280 bar for various mixes are determined and recorded. Table 2 shows the exactness of the estimations and the uncertainty of the determined results of the different parameters. In order to contemplate the impact of fuel IP on the engine performance and outflow attributes, the IT was kept steady at optimized value of $23^{\circ} \mathrm{CA}$ BTDC. The impact of IP 200, 220, 240, 260 and 280 bar were contemplated and results were contrasted with neat diesel. The fuel injector pressure was balanced by expanding or diminishing the preload of the spring inside the injector.

\section{$2.2 \quad$ Fuel}

Pupae oil is made by silkworm pupae got from the sericulture industry. Pupae oil methyl ester (POME) created from transestification were utilized as fuel for leading tests on DI - CI engine. The viscosity of the Pupae oil biodiesel is considerably more than the thickness of diesel along these lines, the viscosity of the POME is decreased by mixing with diesel. The various mixes B0 (Pure diesel), B10, B15, B17, B20, B23, B25, B30, B40, B50, B60, B70, B80, B90 and B100 where B17 implies 17\% (POME) and 83\% (B0) by volume were considered for researching the performance and emission qualities. The properties of the POME are given in the table 3. Diesel and biodiesel mixes were tried at 4.29 bar, BMEP $(2.79 \mathrm{~kW} .80 \%)$ load condition at consistent speed of $1500 \mathrm{rpm}$. Steady cooling water inlet temperature and stream rate were kept up all through the test. During each trail the engine is taken into account certain measure of time to accomplish consistent state condition. All estimations were recorded at various IP 200, 220, 240, 260 and 280 bar. 


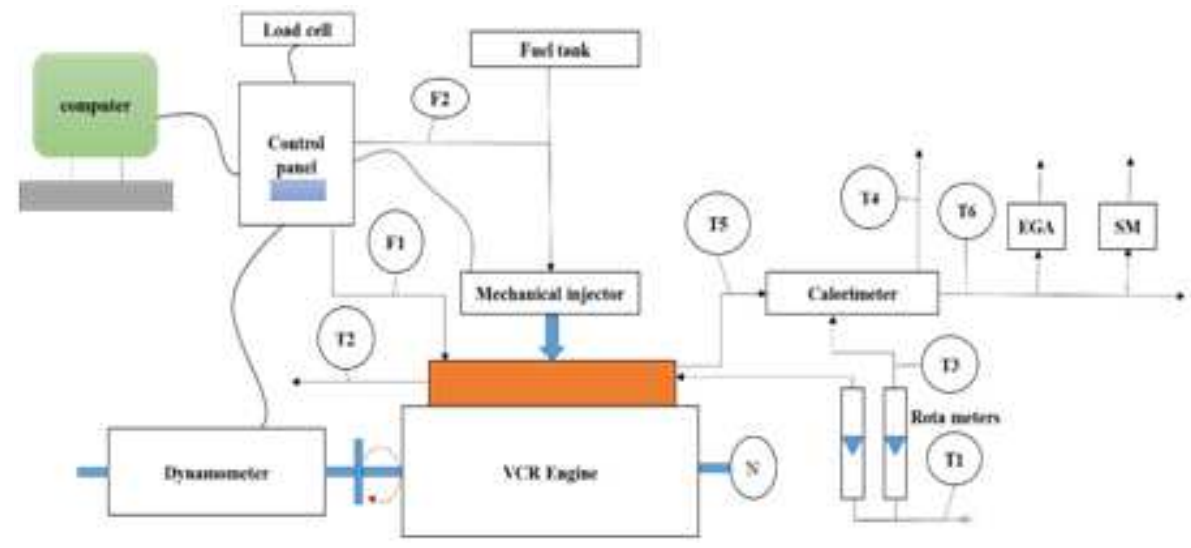

Figure 2: Schematic diagram of engine Test Rig

T1, T3 - Inlet Water Temperature, T2 - Outlet Engine Jacket Water Temperature, T4 -Outlet Calorimeter Water Temperature, T5 - Exhaust Gas Temperature before Calorimeter, T6 - Exhaust Gas Temperature after Calorimeter, F1- air intake differential pressure unit, F2- Fuel Flow unit, N - RPM encoder, EGA - Exhaust Gas Analyzer, SM - Smoke meter

Table 1: Engine details

\begin{tabular}{|l|l|}
\hline \multicolumn{1}{|c|}{$\begin{array}{c}\text { Model and } \\
\text { Make }\end{array}$} & \multicolumn{1}{c|}{ Kirloskar } \\
\hline No. of cylinder & Single \\
\hline Cycle & 4-stroke \\
\hline $\begin{array}{l}\text { Combustion } \\
\text { Chamber }\end{array}$ & Direct Injection \\
\hline $\begin{array}{l}\text { Bore and } \\
\text { stroke }\end{array}$ & $\begin{array}{l}80 \mathrm{~mm} \text { and } 110 \\
\mathrm{~mm}\end{array}$ \\
\hline Rated Power & $\begin{array}{l}3.72 \mathrm{~kW} \text { at } 1500 \\
\text { rpm }\end{array}$ \\
\hline $\begin{array}{l}\text { Compression } \\
\text { ratio }\end{array}$ & $\begin{array}{l}16.5, \text { Modified } \\
\text { to work in range } \\
\text { of 12 to 24 }\end{array}$ \\
\hline Dynamometer & $\begin{array}{l}\text { Eddy current } \\
\text { with loading } \\
\text { unit }\end{array}$ \\
\hline
\end{tabular}

Table 2: The accuracies of the measurements and the uncertainty of the calculated results

\begin{tabular}{|l|l|}
\hline Measurements & Accuracy \\
\hline Engine speed & $\pm 2 \mathrm{rpm}$ \\
\hline Load & $\pm 0.1 \mathrm{~kg}$ \\
\hline Temperature & $\pm 1^{\circ} \mathrm{C}$ \\
\hline $\mathrm{CO}$ & $\pm 0.006 \%$ \\
\hline $\mathrm{CO}_{2}$ & $\pm 0.025 \%$ \\
\hline $\mathrm{HC}$ & $\pm 10 \mathrm{ppm}$ \\
\hline $\mathrm{O}_{2}$ & $\pm 0.04 \%$ \\
\hline NOx & $\pm 15 \mathrm{ppm}$ \\
\hline Time & $\pm 0.5 \%$ \\
\hline
\end{tabular}


Table 3: Properties of fuels

\begin{tabular}{|l|c|c|c|}
\hline \multicolumn{1}{|c|}{ Properties } & POME & Diesel & ASTM Limits \\
\hline Density $(\mathrm{kg} / \mathrm{m} 3)$ & 880 & 841 & $860-900$ \\
\hline Flash Point $\left({ }^{\circ} \mathrm{C}\right)$ & 103 & 64 & $\min 130$ \\
\hline $\begin{array}{l}\text { Kinematic Viscosity } \\
\left(40^{\circ} \mathrm{C}\right)\left(\mathrm{mm}^{2} / \mathrm{s}\right)\end{array}$ & 2.88 & 1.57 & $1.9-6.0$ \\
\hline $\begin{array}{l}\text { Calorific Value } \\
(\mathrm{MJ} / \mathrm{kg})\end{array}$ & 38.13 & 44.5 & $\min 37.5$ \\
\hline Cetane number & 56.43 & 46.4 & $\min 47$ \\
\hline
\end{tabular}

\section{RESULTS AND DISCUSSIONS}

\subsection{Brake Thermal Efficiency}

The impact of injection pressure on BTE is depicted in figure 3. From the figure it is seen that BTE increments with IP up to 260 bar and there after further increment in IP diminishes the BTE. Increment of IP past 260 bar diminishes the fuel droplet size subsequently expands the force got impinging on chamber walls prompting loss of heat through chamber walls [8]. The most extreme BTE was seen at IP of 260 bar for all fuels. The BTE of B0, B17, B23, B50, B100 fuels were estimated as $29.6 \%, 29.2 \%, 29.1 \%, 27.62 \%$ and $26.9 \%$ respectively. From the chart it is additionally seen that the increase of mix proportion diminishes the BTE at consistent IP. This is for the mainly due because of higher viscosity value of POBD fuel contrasted with diesel.

\subsection{Brake Specific Fuel Consumption}

The variation of BSFC with injection pressure is appeared in figure 4. Expanding fuel IP diminishes the BSFC for all fuel mixes up to 260 bar. Expanding the injection pressure builds the atomization of fuel prompting development of homogenous blend results total burning and diminishes the BSFC. Engine when worked at IP over 260 bar shows the pattern in expanding BSFC for all mixes. This might be principally because of fine atomization of fuel at higher IP diminishes the fuel droplet size and increased momentum prompts getting away from burning space results to loss of fuel . This pattern was expanded further at exceptionally high injection pressures [8], [22].

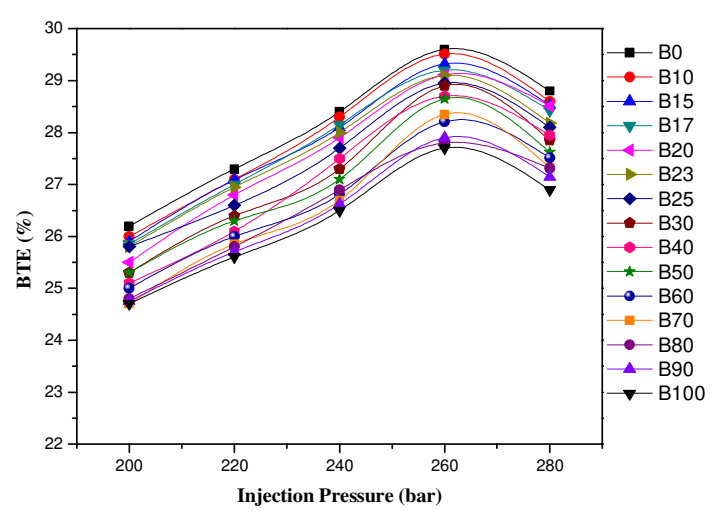

Figure 3: Variation of BTE with fuel injection Pressure

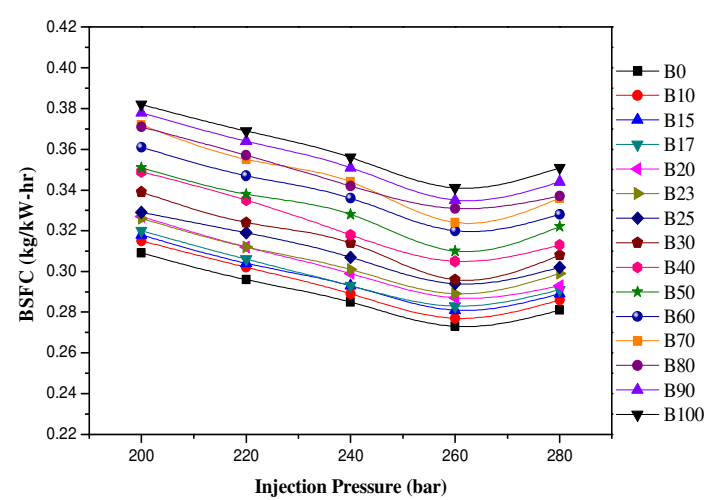

Figure 4: Variation of BSFC with fuel injection Pressure 


\subsection{Exhaust Gas Temperature}

The EGT variation of all fuel mixes with injection pressure is appeared in figure 5. For all fuel mixes it was seen that lower EGT were recorded at lower IP on account of lower IP and improper atomization forms non homogenous blend because of higher fuel droplet size this prompts in complete burning delivering less heat energy. Also at higher IP fine atomization was conveyed and achieves higher energy while entering in to engine chamber and impinging on chamber wall [23], [24]. The loss of heat energy through chamber wall during burning decreases the EGT at high injection pressure. The successful and complete burning was seen at 260 bar IP delivers high temperature exhaust gases. Among all mixes B100 discharges lower EGT as a result of LHV of B100 fuel contrasted with other.

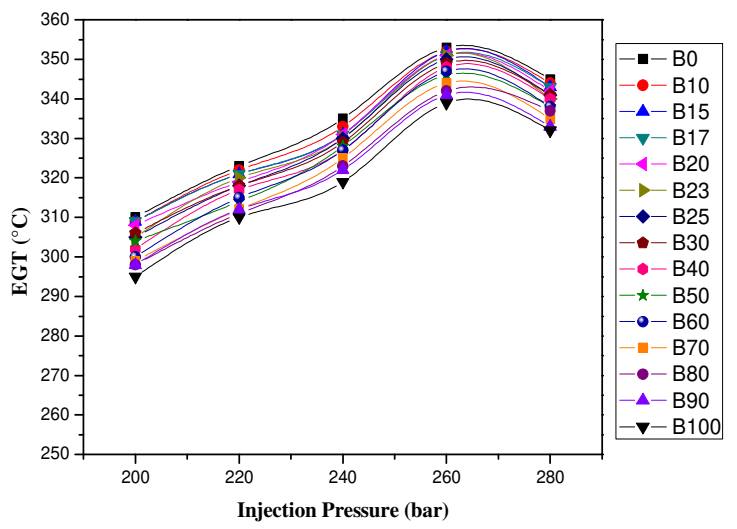

Figure 5: Variation of EGT with fuel injection Pressure

\subsection{Exhaust Emissions}

\subsubsection{Carbon Monoxide Emission}

Figure 6 portrays the variation of $\mathrm{CO}$ emission with fuel injection pressure. From the figure the diminished $\mathrm{CO}$ discharge are seen up to 260 bar IP. Behind and Beyond 260 bar changing IP builds CO discharge for all fuels, as on account of primarily development of $\mathrm{CO}$ emission relies upon the burning cycle and consistently the total ignition came about lower CO outflow. At 260 bar injection pressure the CO outflow are watched least for all the fuel mixes because of complete burning. $\mathrm{CO}$ outflow for biodiesel and its mixes are watched lower than neat diesel. This is likewise a direct result of more oxygen substance of biodiesel prompts complete burning and coming about lower CO discharge [25]..

\subsubsection{Unburnt Hydrocarbon Emission}

The UHC discharge variation with fuel injection pressure is appeared in figure 7. From the diagram it was researched that UHC discharge in the fumes diminishes with IP from 280 bar to 260 bar and under 260 bar diminishing IP expands UHC outflow. The least UHC discharges were watched for all mixes at 260 bar. This is for the most part because of more viable burning at 260 bar. In any case, at all pressures biodiesel and it mixes produce less UHC is because of the oxygenated fuel of biodiesel, it prompts a more complete burning. The higher cetane number of biodiesel fuel diminishes delay period prompting lower UHC emissions. Hence, the higher oxygen content and cetane number of biodiesel-diesel fuel mixes will in general lessen UHC outflows when contrasted with neat diesel [26].

\subsubsection{Nitrogen Oxides Emission}

As biodiesels contain 10-12\% higher oxygen contrasted with diesel fuel. POME likewise contains more oxygen than diesel 
which is obvious for more NOx emission in the fumes as appeared in figure 8. NOx outflows of POME and its mixes promote reaction of nitrogen present in the conceded air with oxygen in the biodiesel produce more NOx discharges. NOx outflows increments for all fuels with IP up to 260 bar, behind and past 260 bar further change in IP diminishes the NOx emission. This is a direct result of non-homogenous blend development because of less atomization of fuel results inadequate burning of fuel at lower IP and even at higher IP likewise loss of fuel because of higher momentum lessen the oxygen accessibility for ignition came about lower NOx outflow [27], [28].

\subsubsection{Smoke Opacity}

The impact of IP on smoke opacity for Pupae biodiesel and its mixes with Diesel is appeared in Figure 9. The smoke diminishes with increment in IP for every single tested fuel. It is likewise observed that smoke opacity diminishes with increment in blend proportion at any consistent IP. Addition of biodiesel to diesel fuel, expands the oxygen content, decreases the aromaticity of the mix, decrease in heating value, flame emissivity, UHC and propensity to soot development. Therefore biodiesel and their mixes produce less thick smokes contrasted with diesel fuel [29], [30]. It is lower for pupae biodiesel by $17.69 \%$ when contrasted with that of diesel oil at an IP of 260 bar. As the IP increments from 200 to 260 bar the smoke lessens by $27.7 \%$ and $25.17 \%$ for diesel oil and pupae biodiesel respectively..

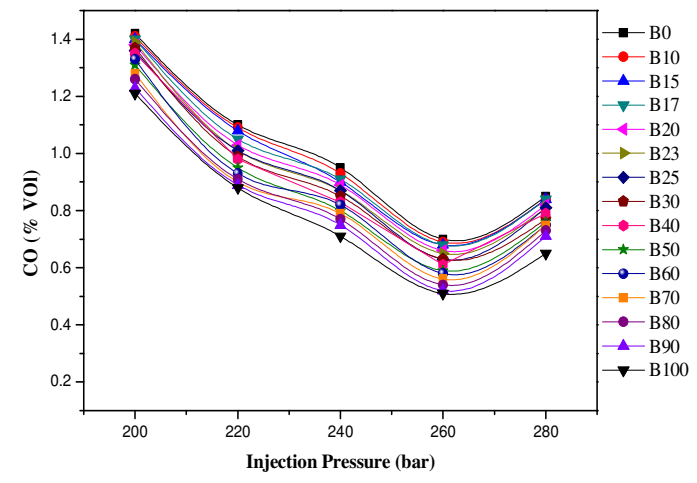

Figure 6: Variation of $\mathrm{CO}$ with fuel injection Pressure

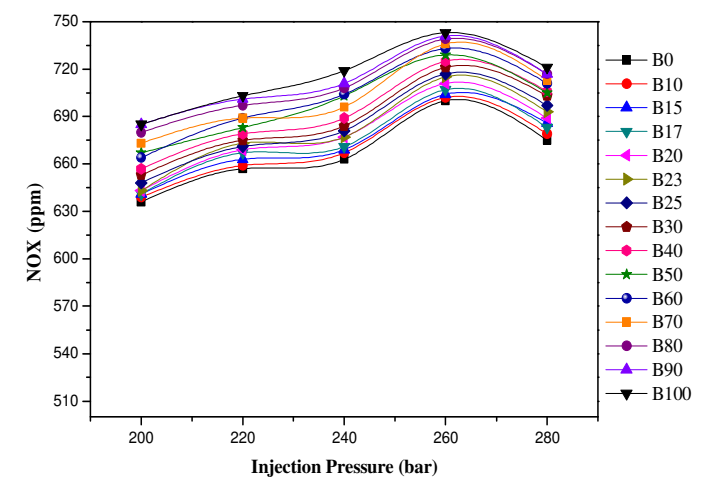

Figure 8: Variation of NOX with fuel injection Pressure

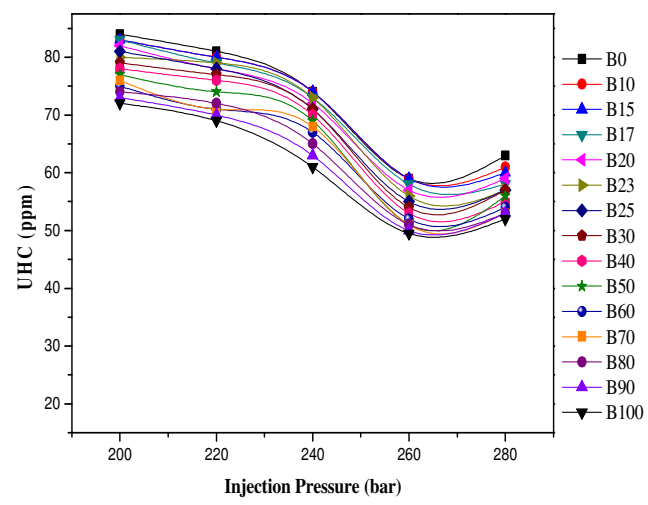

Figure 7: Variation of UHC with fuel injection Pressure

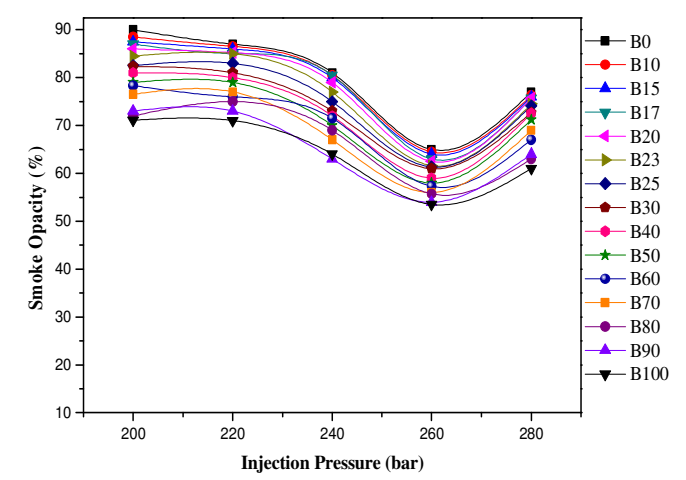

Figure 9: Variation of Smoke Opacity with fuel injection Pressure

Engine was made to run with each and every different blend at different IP adequately and the accompanying ends are 
drawn from preliminary assessment.

- BSFC is low at 260 bar and after 260 bar, increment of injection pressure BSFC increments. At higher injection pressures BSFC is expanded due to higher force of fuel got encroaches on chamber walls prompts wastage of fuel and inappropriate ignition.

- The BTE of B0, B17, B23, B50, B100 fuels were estimated as $29.6 \%, 29.2 \%, 29.1 \%, 27.62 \%$ and $26.9 \%$ respectively at 260 bar IP which are higher contrasted with other IP. This was mostly because of complete ignition of whole fuel which was conceded with no wastage with higher momentum. BTE of the engine brought down by $2.7 \%$ with POME contrasted with diesel operation.

- It was seen that lower EGT were recorded at lower IP. Decrease in EGT in correlation with diesel was 3.96\% at 260 bar.

- NOx discharges increments for all fuels with increment of IP up to 260 bar. Despite the fact that at 260 bar NOX discharges were higher for POME than for diesel by 5.78\%.

- The most reduced UHC and CO discharges were seen at 260 bar contrasted with different pressures. So decreases in UHC and CO discharges in examination with diesel were $16.10 \%$ and $28.16 \%$ respectively at 260 bar.

- For 260 bar pressure decrease in smoke outflow in examination with diesel was $11.5 \%$. Finally a fuel IP of 260 bar was discovered to be ideal for POME and its mixes activity. So Experiments with POME and its mixes, for longer periods of operation, it is smarter to work the engine with POME than neat diesel.

- In view of the comprehensive engine tests, it could be inferred that the mixes of Pupae oil methyl ester (POME) with diesel fuel could supplant the diesel at optimum IP of 260 bar for running the current diesel engine with no equipment adjustments and $17 \%$ and $23 \%$ mixes of pupae oil methyl ester with diesel fuel was discovered to be the best mixes as to performance and emission attributes among all mixes. Additionally it could be reasoned that the biodiesel lessens the environmental impacts of transportation, diminish the reliance on raw petroleum imports and offer business prospects to sericulture ventures for times of overabundance sericulture production. So it very well may be the right solution for India. This will subsequently help in controlling air contamination generally.

1. C. Pinto et al., "Biodiesel: An overview,” Journal of the Brazilian Chemical Society, vol. 16, pp. 1313-1330, 2005.

2. Y. M. Sani, et al., "Biodiesel Feedstock and Production Technologies: Successes, Challenges and Prospects," Biodiesel Feedstocks, Production and Applications, 2012.

3. Demirbas, et al., "Biodiesel production from non-edible plant oils," Energy Exploration and Exploitation, vol. 34, pp. 290$318,2016$.

4. M. K. Yesilyurt, et al., "The performance, emissions, and combustion characteristics of an unmodified diesel engine running on the ternary blends of pentanol/safflower oil biodiesel/diesel fuel," Springer International Publishing, vol. 140, 2020.

5. C. Ahmia, et al., "Raw material for biodiesel production. Valorization of used edible oil," Revue des Energies Renouvelables, vol. 17, pp. 335-343, 2014.

6. P. Tamilselvan, et al., "A comprehensive review on performance, combustion and emission characteristics of biodiesel fuelled diesel engines," Renewable and Sustainable Energy Reviews, vol. 79, pp. 1134-1159, 2017. 
7. Xu, et al., "The influence of injection timing on emissions characteristics of a DI diesel engine fuelled with pistaciachinensisbunge seed biodiesel," Advanced Materials Research, vol. 634-638, pp. 846-851, 2013.

8. K. B. Mutyalu, et al., "Effect of Fuel Injection Pressure on Performance and Emission Characteristics of DI- CI Engine with SheaOlein Biodiesel," Materials Today: Proceedings, vol. 5, pp. 494-500, 2018.

9. Anbarasu and A. Karthikeyan, "Effect of injection pressure on the performance and emission characteristics of CI engine using canola emulsion fuel," International Journal of Ambient Energy, vol. 38, pp. 314-319, 2017.

10. M. S. Shehata, et al., "Corn and soybean biodiesel blends as alternative fuels for diesel engine at different injection pressures," Fuel, vol. 161, pp. 49-58, 2015.

11. G. Jamuna Rani, et al., "Investigation of fuel injection pressure impact on ci engine performance and emissions using biodiesel blend with alumina nano additives," International Journal of Mechanical Engineering and Technology,vol. 9, pp. 922-928, 2018.

12. H. Y. Kim, et al., "Effects of fuel injection pressure on combustion and emission characteristics under low speed conditions in a diesel engine fueled with palm oil biodiesel," Energies, vol. 12, 2019.

13. S. V. Channapattana, et al., "Effect of Injection Pressure on the Performance and Emission Characteristics of VCR engine using Honne Biodiesel as a Fuel," Materials Today: Proceedings, vol. 2, pp. 1316-1325, 2015.

14. ThalariVasantha, and M. L. S. Deva Kumar, "Effect of Fuel Injection Pressure on Performance and Emission Characteristics of Diesel Engine Fueled with Cashew Nut Shell Biodiesel," International Journal of Science and Research, vol. 4, pp. 621-626, 2015.

15. K. Muralidharan and P. Govindarajan, "The effect of bio-fuel blends and fuel injection pressure on diesel engine emission for sustainable environment," American Journal of Environmental Sciences , vol. 7, pp. 377-382, 2011.

16. K. Nanthagopal, et al., "Influence of fuel injection pressures on Calophylluminophyllum methyl ester fuelled direct injection diesel engine," Energy Conversion and Management, vol. 116, pp. 165-173, 2016.

17. T. Hariprasad, "Effect of injection pressure on performance of dual fuel diesel engine," SAE Technical Papers, vol. $12,2013$.

18. Pradip. Lingfa, et al., "Effect of Injection Pressures and Injection Timings on the Engine Performance and Emissions on Single Cylinder Diesel Engine Operating with Tung Biodiesel Blends, "SAE Technical Papers, 2014.

19. Preetham Churkunti, et al., "Influence of Fuel Injection Pressure and Biodiesel upon NOx Emissions," SAE Technical Papers, 2016.

20. T. Basavaraja, et al., "Effect of Injection Pressure on Emission Performance of Bio-diesel and its Blends," SAE Technical Papers. 2005

21. N. S. Gahlot and N. Suryanarayana, "Utilization of secondary waste products of silk industry," International Conference on Bioengineering, Biotechnology and Environment protection- S.C. Bioing S.A. - Bucharest, pp. 66-70, 2008.

22. M. R. Indudhar, et al., "Effects of single and split injection on the performance, emission and combustion attributes of a CRDI engine powered with diesel and honge biodiesel," Sustainable Energy and Fuels, vol. 3, pp. 2275-2286, 2019.

23. H. Y. Kim, et al., "Effects of fuel injection pressure on combustion and emission characteristics under low speed conditions in a diesel engine fueled with palm oil biodiesel," Energies, vol. 12, 2019.

24. H. Venu and M. Dinesh Babu, "Improvement of ternary fuel combustion with various injection pressure strategies in a toroidal re-entrant combustion chamber, "Environmental Science and Pollution Research, vol. 25, pp. 32024-32043, 2018. 
25. M. Qasim, et al., "Combustion, performance, and emission evaluation of a diesel engine with biodiesel like fuel blends derived from a mixture of Pakistani waste canola and waste transformer oils, "Energies, vol. 10, 2017.

26. S. Islam, et al., "Study on Emission and Performance of Diesel Engine Using Castor Biodiesel," Journal of Chemistry, vol. 2014, pp. 1-8, 2014.

27. J. Han, et al., "Experimental study of the combustion and emission characteristics of oxygenated fuels on a heavy-duty diesel engine," Fuel, vol. 268, pp. 117219, 2020.

28. P. Singh, et al., "Fuel-Injection Strategy for PCCI Engine Fueled by Mineral Diesel and Biodiesel Blends," Energy and Fuels, vol. 31, pp. 8594-8607, 2017.

29. J. Wang, et al., "Combustion and Emission Characteristics of a Diesel Engine Fueled with Diesel-Rocket Propellant-3 Wide Distillation Blended Fuels,” Journal of Energy Engineering, vol. 146, pp. 1-9, 2020.

30. B.K. Venkanna and C. Venkataramana Reddy, "Effect of Injector Opening Pressure on Performance, Emission and Combustion Characteristics of DI Diesel Engine Fueled with Diesel and Honne Oil Methyl Ester,” Environmental Progress \& Sustainable Energy, pp. 1-8, 2011. 

